\title{
Semiautomated Device for Plucking of Flower Buds
}

\author{
L.Megalan Leo, A.Jerrin Simla
}

\begin{abstract}
Indians are celebrating more number of festivals than any other country. In festival celebrations, flowers are used as a prime element. Without flowers we will not celebrate even single festival. Most popular flowers in south India is Nerium oleander, jasmine, rose, etc. These flowers are demanded high among the flowers due to its fragrance. Another added advantage is its less cost. Though it has many advantages, certain drawbacks limit the business. One major problem is plucking flower at the right time. It is very difficult task because the workers must pluck the flowers before its blossom. So, they have to pluck early morning around 4'o clock under weak light condition. At weak light condition workers may not able to identify the insects and snakes. Because of this workers efficiency is reduced as well as some of them died. To overcome this problem, we proposed a device for plucking and packing of flower buds. The proposed device can able to move forward, backward and rotate. Camera with light is used to capture the image of the flower bud. Image processing technique is used to match the image of the bud. Robot arm is used to pluck the bud. Container is used to pack the buds. The proposed device is a waterproof device.
\end{abstract}

Keywords - Robot, automation, plucking, arm processor, Raspberry Pi, Embedded System, IOT.

\section{INTRODUCTION}

In today's modern world technology has been increasing day by day. As flowers are used as a prime element for the celebrations in India, flowers are grown in large scale. One of the most popular flowers in India is Nerium oleander. This flower has been used in most of the celebrations in India. So, the demand for Nerium Oleander is high. This flower will be in demand when it was in the bud stage. This paper is keeping in view the situation of workers in the fields. The main idea of this device is to pluck the buds with maximum safety and secure the workers from the risky environment.

Mir Sajjad Hussain Talpur et al has done a microcontroller based reliable and high performance robotic system for food / biscuit producing line. Unbaked biscuits tray is placed into furnace by robot. Biscuit tray is taken out from the furnace after it is baked. A special type of gripper is made to pick and place the biscuits tray with flexibility [1]. Mohamed naufal Bin has did a research on the Pick and Place Robotic Arm Controlled by Computer.

Revised Manuscript Received on December 15, 2019.

L.Megalan Leo, Department of Electronics and Telecommunication Engineering Sathyabama Institute of Science and Technology Chennai,India.rmegalanleo@gmail.com

A.Jerrin Simla, Department of Computer Science Engineering Panimalar Institute of Technology Chennai,India jerrinsimla@gmail.com

Agnes Shifani, Department of Electronics and Communication Engineering Jeppiaar maamallan engineering college Chennai,India. agnesshifani@gmail.com
He has focused on 5 DOF articulated arm since it mimics to human arm. Controller circuit board is based on Microchip's popular programmable integrated circuit (PIC) 16F84A flash programmable microcontroller [2]. Anusha Ronanki et al designed a Pick and place robot to take books in the library. The process consists of robotic arm along with grippers capable of moving in the three axes and an ATMEGA 8 microcontroller. [3]. A. Che Soh et al designed an adjustable gripper for robotic picking and placing operation. To carry different size or shape, the user needs to replace gripper which are more time absorbing and more expensive [4]. Abinav Sinha has done an efficient control scheme that can be applied to industrial pick and place robotic manipulators. The mathematical model of this industrial pick and place system is based on the concept and inverted pendulum on a moving cart whose movement is restricted in horizontal direction [5]. V. Vonasek has done the project, In the bin picking problem, the task is to automatically unload objects from a container using a robotic manipulator. [6]. H.Yin has done a soft robot gripper, which possesses variable stiffness resulting from shape memory alloy (SMA) -1 fiber and actuated by SMA-2 wires [7]. Tolley has done the combination of fluidic elastomer actuators and geckoinspired adhesives to both enhance existing soft gripper properties and generate new capabilities [8]. Castro has designed as a first prototype to bring technology closer to young students and schools, UNED has developed a Arduino based smart device that facilitates the integration of remote laboratories in learning scenarios. [9]. Fernandez has done a project which analyzes how a remote robotic laboratory can act like nexus between pregraduate students and real engineering. [10]. Carro Fernandez has designed the project which analyzes the impact of the introduction of robotics in industry today and its impact on workers and their unions. It states that the efficiency and quality can be improved. At the same time it leads to unemployment problem in the industry [11].

\section{EXPERIMENTAL METHOD}

Main objective of the work is to pluck the flower buds using robot. The device is designed as a Raspberry Pi controlled robot with camera to capture the image, Image processing technique to match the image, robotic arm to pluck the flower bud and a container to collect the buds. User is staying away from the garden. Remote device is the robot which moves towards the flower areas. Robot captures the image using camera and it sends to the user over a network. User compares the image size with the existing dataset images by running the image processing software. Bud is in the required size means control signal will be activated by the remote user.

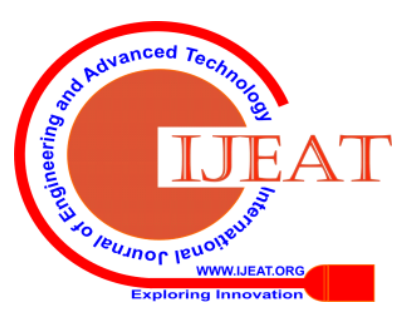


After getting the command from the remote user, robot extends the arm of it and plucks the flower buds. Flower buds are collected by a tray which is available with robot. We can control this robot from home itself through pc. The Robot is used for Plucking of flower buds using Raspberry $\mathrm{Pi}$. This robot provides a remote monitoring and controlling application for analysis of particular flower buds. Block diagram of the experimental method is shown in figure 1. Device consists of robotic arm, DC geared motors and Raspberry pi. Arm consists of Servo motor for plucking the bud and movement of the arm. DC motors is used for the upward and downward movement of arm.

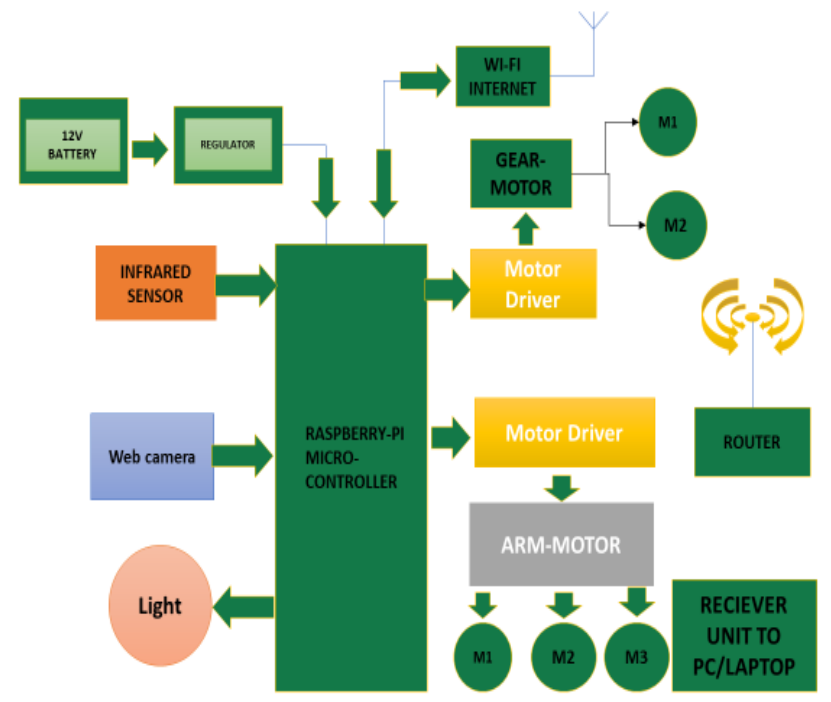

Figure 1: Block Diagram

It consists of Ultrasonic sensors and IR sensor. The Ultrasonic sensors are used to measure distance and infrared sensors are used to detect obstacle in path. This sensor send signal to raspberry pi. Stepper motor is used here to provide turning mechanism, but the accuracy is limited. In addition DC motor is used to control the movement of the base of the robot. Stepper motors and DC motors are controlled by raspberry pi which are connected through driver circuit. 2 motors controlled by single drive circuit. Raspberry $\mathrm{Pi}$ is connected with drive circuit through GPIO. Driver circuit has its own power supply of $5 \mathrm{~V}$. GPIO ports are used to enable motor driver.

Flowchart of the designed robot is shown in figure 2. Camera is switched on by receiving the command from remote user. It receives the command to move on the direction left or right, forward or reverse. After reaching the nearby place to the bud it opens the gripper. After adjusting the gripper in proper direction, gripper closes and plucks the bud. Buds are stored in the basket. The above operation is repeated to till the job completion.

\section{RESULT AND DISCUSSION}

In our model we are building a semi automated pick and place robot with gripper controlled by servo motors. Robot would be a kind of humanoid robot with robotic arms and with a four wheeled base. Figure 3 shows the circuit of the implemented design. Power supply is given to transformer which converts AC $230 \mathrm{~V}$ supply into DC voltage. It is regulated by the regulator. It consists of night vision camera so it can use in dim light. Camera is interfaced with the raspberry controller. It consists of four wheels and it can rotate 360 degree. It consists of arm it is used to pluck and collect the flower. Location and the bud quality are identified with the help of image sensor and image processing software.

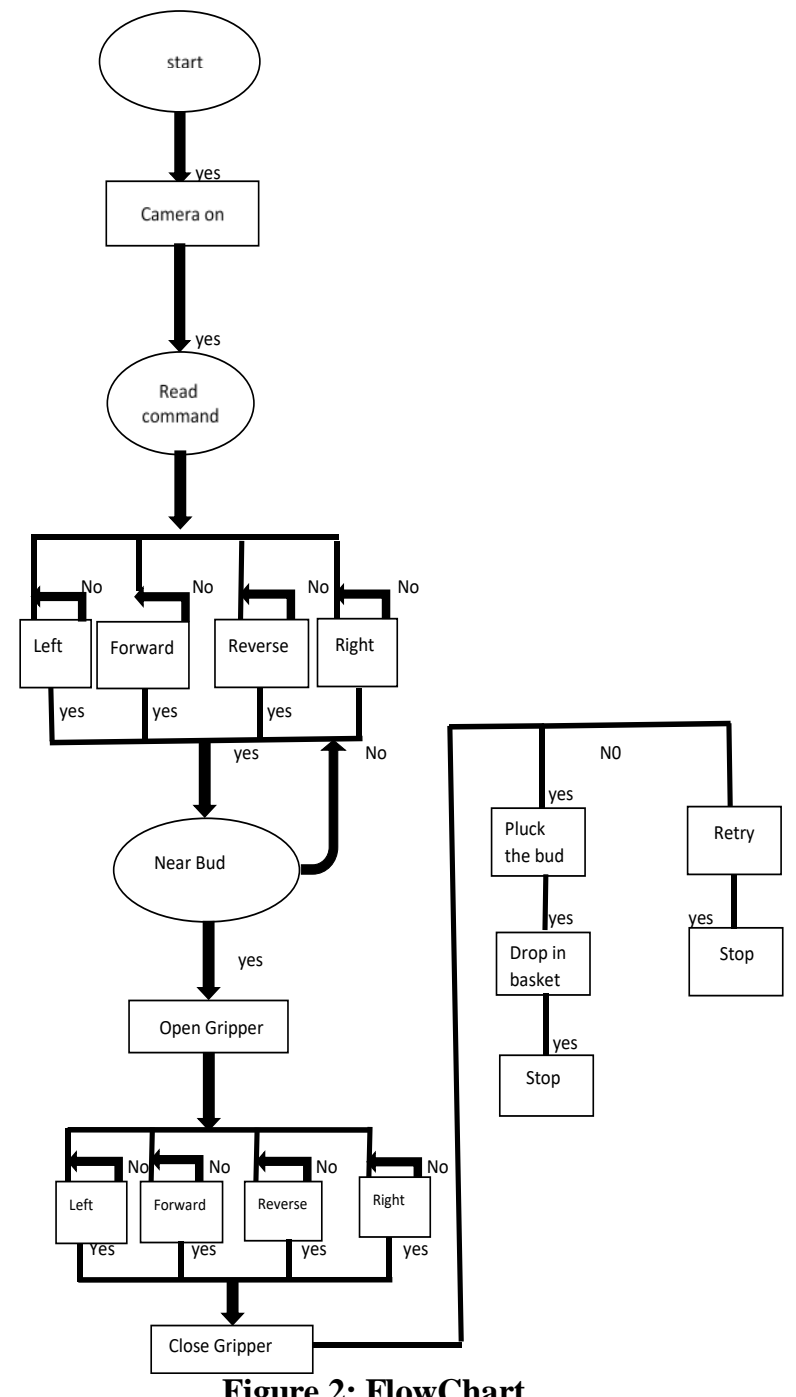

Figure 2: FlowChart

Collected buds will be stored in a weighing basket. Once it reaches $1 \mathrm{~kg}$, buds will be packed by using packing mechanism.

Here raspberry pi is the main controller which control python, which in turn controls servo driver to drive all servo motors. Whole robot with body and with 4 wheels using 2 high torque dc motors driven by L239D IC controlled by python. The hotspot module has a controlling range of 10 meters. Whole robot control is based on the signals sent by user over Hotspot and raspberry pi receiving and controlling all other components including python is based on the programming done. Each servo can use by 360 -degree angle rotation, which in turn use to change the position of the joints of arms and grippers. We have used the power between servo and DC motors by effective circuit design. Power source we are using here is $12 \mathrm{~V} \mathrm{Li-Po} \mathrm{battery.} \mathrm{It} \mathrm{will}$ last at least maximum for 7 hours. Robot functions are tested to plug the specific flower bud in early morning. Since our robotic arm is adjustable by various lengths so it can plug the flower bud in upward and downward direction. Image processing technique is used to identify the correct stage of the flower which device has to plug. It is interfaced with the Wi-Fi module. 
Since our project is semiautomatic device, so there is reducing the processing time, complexity, and power consumption and there is no loss of workers in the field. As our robot is semi automated controlled device, it always requires a labour to operate it. But unlike fixed programmed robots, our robot will perform plugging, image detection, water proof, night vision camera, it can rotate 360-degree angle.

It gives required power supply to motors based on operation defined by program. Wireless night vision camera would be able to capture the flower buds in dim light. Robotic arms move in front direction where flower buds are present. After reaching the flower bud, Arm stabilizes itself and then moves in downwards direction to pick that flower bud. Plugging movement of robotic arm is done by Motors. After plucking the flower bud the arm collect the flower bud in a container.

Table 1: Advantages and disadvantages of different machines

\begin{tabular}{|c|c|c|}
\hline Machine & Advantages & Disadvantages \\
\hline $\begin{array}{l}\text { Hand-held single- } \\
\text { or two-man }\end{array}$ & $\begin{array}{l}\text { No field preparation required, } \\
\text { highly adaptable, relatively } \\
\text { cheap to run }\end{array}$ & $\begin{array}{l}\text { Leaf quality highly dependent on operator } \\
\text { desire, needs strong operators. } \\
\text { Productivity limited due to nature of } \\
\text { physical work. No forward speed } \\
\text { control }\end{array}$ \\
\hline $\begin{array}{l}\text { Modified hand- } \\
\text { held with skids }\end{array}$ & $\begin{array}{l}\text { No field preparation required, } \\
\text { highly adaptable, relatively } \\
\text { cheap to run }\end{array}$ & $\begin{array}{l}\text { Leaf quality less dependent on operator } \\
\text { desire, needs strong operators. } \\
\text { Productivity limited due to nature of } \\
\text { physical work. No forward speed } \\
\text { control }\end{array}$ \\
\hline $\begin{array}{l}\text { Rickshaw - } \\
\text { manually } \\
\text { pulled }\end{array}$ & $\begin{array}{l}\text { Removes a lot of operator } \\
\text { influence on leaf quality, } \\
\text { depending on design. Highly } \\
\text { manoeuvrable, requiring } \\
\text { limited tuming circles. Low } \\
\text { capital costs. Running costs } \\
\text { the same as hand-held }\end{array}$ & $\begin{array}{l}\text { Requires a good degree of field } \\
\text { preparation, although not too much in } \\
\text { terms of field access if a six-foot }(1.8 \mathrm{~m}) \\
\text { wide row is sacrificed for headland } \\
\text { turning. Very tiring in undulating } \\
\text { conditions, limits productivity. } \\
\text { No forward speed control }\end{array}$ \\
\hline $\begin{array}{l}\text { Rickshaw - } \\
\text { mechanical } \\
\text { drive system }\end{array}$ & $\begin{array}{l}\text { Removes all of operator } \\
\text { influence on leaf quality. } \\
\text { Very good manoeuvrability, }\end{array}$ & $\begin{array}{l}\text { Requires a good degree of field } \\
\text { preparation, although not too much in } \\
\text { terms of field access if a six-foot }(1.8 \mathrm{~m})\end{array}$ \\
\hline
\end{tabular}

requiring limited turning circles. Modest capital costs. Running costs slightly higher than hand-held

\section{Four wheel, self- Removes all of operator propelled units influence on leaf quality. Can have good manoeuvrability if using skid steering. Can carry a reasonable quantity of green leaf to the field headland, good for long runs \\ Large-capacity A complete solution to harvest, units forward speed control and loading of transporter}

wide row is sacrificed for headland turning. Not as manoeuvrable in and out of field as the manually pulled unit due to increased machine weight. Must also be more productive to cover additional capital costs

Without four-wheel drive and some form of floating beam axle, not good on undulating conditions as loses traction. A considerable level of field and headland preparation required. Unit costs can be high if time in work is not maximised, difficult to do unless fields are ideally planted for mechanisation Can only be used on flat land, generally specifically planted for mechanised operations due to high capital costs and low capacity to cope with tight headlands or steep banks. Upwards of $15,000 \mathrm{~kg}$ of green leaf per day would be required to justify such a unit. Because of high capital costs, often not affordable to have any redundancy in the system, so maintenance is a considerable challenge

\section{CONClusion}

The device is controlled by IOT online communication through PC. The objective of the device has accomplished with PC control application. Device is an eco-friendly product which can operate by electrical power. It is a waterproof device so it can use in a rainy season too. The PC control system allows the robot arm near to the field. The controller here used in this system enriches the python program so controls the task are easily programmed. In feature we implement this same project as automatic device. This work is the implementation of plucking of flower bud using Raspberry Pi, IR sensor, microcontroller, Wi-Fi module. The PC control system allows the robot arm near to the field. It allows the user to pluck the flower buds using the robotic arm. It provides the visual feedback from the site of the flower buds. It also provides a user friendly control application. Our work is an efficient step towards the user friendly control application and encourages the people in rural areas to get knowledgeable.

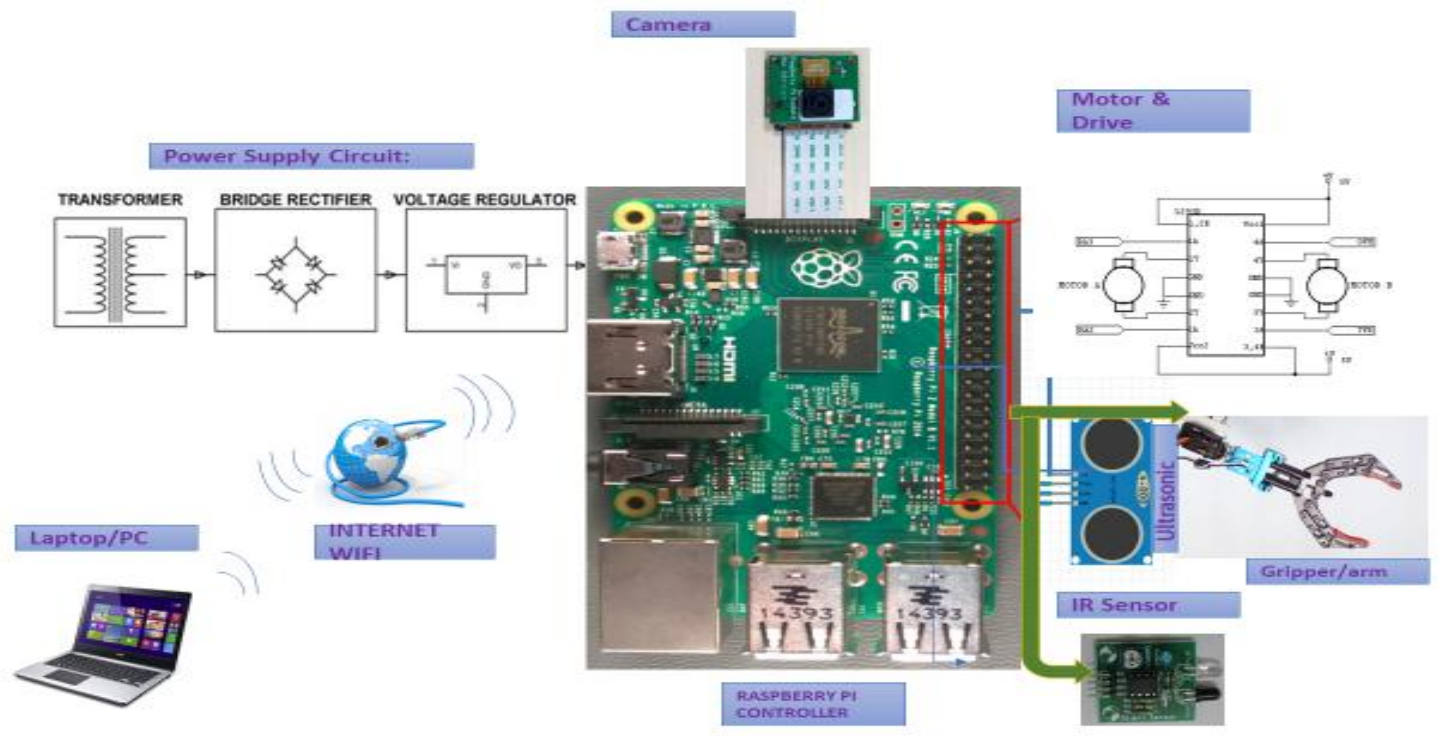

Figure 3: Circuit Diagram 


\section{REFERENCE}

1. Mir Sajjad Hussain Talpur, Murtaza Hussain Shaikh. Automation of Mobile Pick and Place Robotic System for Small Food Industry. IEEE Digital Library.978-1-4577-1139: pp. 522-526, 2012.

2. Mohamed Naufal bin Omar," Pick and place robotic arm controlled by Computer", Universitite knika Malaysia, Melaka April 2007.

3. Anusha ronanki, m. Kranthi, "Design and fabrication of pick and place robot to be used in library", international journal of innovative research in science, engineering and technology, Vol. 4, Issue 6, June 2015, DOI:10.15680/IJIRSET.2015.0406056.

4. Che soh, s.a. Ahmad, a.j. Ishak and k. N. Abdul latif," Development of an adjustable gripper for robotic picking and placing operation", International journal on smart sensing and intelligent systems, vol. 5, no. 4, December 2012.

5. Sinha, R. K. Mishra, and S. Jaiswal, "Robust and Smooth Nonlinear Control of an Industrial Robot for Automated Pick and Place", 2015 International Conference on Computing Communication Control and Automation, 2015.

6. V. Vonasek, A. Vick, and M. Saska, "Motion planning with motion primitives for industrial bin picking, "22nd IEEE International Conference on Emerging Technologies and Factory Automation (ETFA), 2017.

7. H. Yin, X. Zhang, J. Li, and J. Cao, "Grasping model and experiment of a soft robot gripper with variable stiffness," 2017 IEEE International Conference on Cybernetics and Intelligent Systems (CIS) and IEEE .

8. Glick, P., Suresh, S., Ruffatto, D., Cutkosky, M., Tolley, M. and Parness, A.. "A Soft Robotic Gripper with Gecko-Inspired Adhesive". IEEE Robotics and Automation Letters, 3(2), 2018, pp.903-910.

9. Carro, G.; Castro, M.; Sancristobal, E.; Diaz, G.; Mur, F.; Latorre, M.; haparro, M.; Lopez-Rey, A.; Salzmann, C.; Gillet, D., "The color of the light: A remote laboratory that uses a smart device that connects teachers and students," Global Engineering Education Conference (EDUCON), 2014 IEEE, vol., no., pp.854,860, 3-5 April 2014 doi:10.1109/EDUCON.2014.682.

10. Fernandez, G.C.; Gil, M.C.; Perez, F.M., "Remote robotic laboratory as nexus between students and real engineering," Interactive Collaborative Learning (ICL), 2012 15th International Conference on, vol., no.,pp.1,4, 26-28 Sept. 2012 doi: 10.1109/ICL.2012.6402136

11. Carro Fernandez, G.; Gutierrez, S.M.; Ruiz, E.S.; Gil, M.C.; Perez, F.M, Formation in robotics, the key to integration in industrial environments, "Interactive Collaborative Learning (ICL), 2012 15th International Conference on, vol., no., pp.1,4, 26-28 Sept. 2012 doi: 10.1109/ICL.2012.6402135

12. HTTP Protocol, reference site: http://www.w3.org/Protocols/ consulted on 8th January 2015.

13. Fernandez, G.C.; Gil, M.C.; Perez, F.M., "Remote robotic laboratory as nexus between students and real engineering," Interactive Collaborative Learning (ICL), 2012 15th International.

14. Raspbian, official site: http://raspbian.org/ consulted on 8th January 2015.Node.js, official site: http://nodejs.org/ consulted on 8th January 2015.

15. Tornado, official site: http://www.tornadoweb.org/en/stable/ consulted on 8th January 2015.

16. NPM repository, official site: https://www.npmjs.com/ consulted on 8th January 2015.

17. Carro Fernandez, G.; Gutierrez, S.M.; Ruiz, E.S.; Gil, M.C.; Perez, F.M., "Formation in robotics, the key to integration in industrial environments, "Interactive Collaborative Learning (ICL), 2012 15th International Conference on, vol., no., pp.1,4, 26-28 Sept. 2012.

18. Sinha, R. K. Mishra, and S. Jaiswal, "Robust and Smooth Nonlinear Control of an Industrial Robot for Automated Pick and Place", 2015 International Conference on Computing Communication Control and Automation, 2015. 